\title{
BOND STRENGTH AND MICROMORPHOLOGICAL FEATURES OF DENTIN SUBSTRATES TREATED WITH DIFFERENT ETCHING MODES USING UNIVERSAL ADHESIVE SYSTEM
}

\author{
Ahmed Adel A. Aziz* and Ahmed Hamdy Abdo**
}

\begin{abstract}
This in-vitro study assessed bond strength and micromorphological features of dentin substrates treated with different etching modes using universal adhesive system. A total of 28 freshly extracted human molars with coronal dentin caries were used for this study. A total of 80 composite microcylinders with prepared dentin surface containing both sound dentin and carious affected dentin were divided into two main groups (40 each) according to the bonding mode used: Self-etch mode in one step single dose, and total-etch mode in two steps. Each group was then subdivided into two subgroups (20 specimens each) according to the type of dentin substrate used: Sound dentin and caries affected dentin. For the Scanning Electron Microscope (SEM) examinations, the teeth were divided into two main groups ( 8 each) according to the bonding mode used: Self-etch mode in one step single dose, and total-etch mode in two steps. Each group was then subdivided into two subgroups (4 specimens each) according to the type of dentin substrate used: sound dentin and caries affected dentin. The interfacial zone was examined using SEM at magnification $5000 \mathrm{X}$. Data was then recorded, tabulated and statistically analyzed. For sound dentin using total-etch mode $(24.02 \pm 1.03 \mathrm{MPa})$ showed statistically significantly lower $\mu \mathrm{SBS}$ than that using self-etch mode $(28.04 \pm 1.30 \mathrm{MPa})$ at $\mathrm{p}<0.05$. For caries affected dentin using total-etch mode $(18.46 \pm 0.86 \mathrm{MPa})$ showed statistically significantly higher mean $\mu$ SBS than that using self-etch mode $(16.48 \pm 0.84$ $\mathrm{MPa}$ ) at $\mathrm{p}<0.05$. Independent of the etch mode used for bonding, sound dentin showed statistically significantly higher mean $\mu$ SBS than that of caries affected dentin at $\mathrm{p}<0.05$. These results were confirmed by the examination of the SEM images which revealed increase in number and length of resin tags for the groups showing high $\mu$ SBS. In conclusion, using self-etch universal adhesives on sound dentin is considered to be material dependent. And using total-etch mode of universal adhesive on caries affected dentin can enhance bond strength. Moreover, the type of substrate and etching strategies may affect the bonding performance and durability of restorations in dentistry.
\end{abstract}

\footnotetext{
* Lecturer of Conservative Dentistry, Faculty of Dentistry, Egyptian Russian University, Cairo, Egypt

${ }^{* *}$ Lecturer of Conservative Dentistry, Faculty of Dentistry, Fayoum University, Cairo, Egypt
} 


\section{INTRODUCTION}

The evolution of the science of bondodontics had totally revolutionized restorative dentistry. Multiple factors have a direct effect on adhesion in dentistry, from which are the substrate type, the adhesive substance type, oral environmental conditions and the skills of the operator who perform the bonding procedures ${ }^{[1]}$.

Bonding procedures was executed, typically, on enamel and dentin to attain adequate bond strength. Enamel was considered a highly mineralized tissue with high bond strength values. On the contrary, dentin was a more complex substrate as it contains minerals, organic matrix and water. Hence, bonding to dentin substrate remained a challenge for clinicians to achieve a proper bond to that of enamel and to allow proper adhesive infiltration inside demineralized dentin substrate ${ }^{[1]}$.

The simpler the application processes, the more advantageous it is for clinicians. Therefore, the advancement in more effective adhesive systems and their application procedures was an effort to shorten the steps of the clinical bonding protocol ${ }^{[2,3]}$. Based on this, there were two major techniques that were developed: total-etching and self-etch techniques. The total-etch technique was advocated by the total removal of the smear layer from the two substrates, the enamel and dentin surfaces, and then was followed by the application of the bonding agent. This technique can be two steps or three steps. However, the self-etch technique eliminates the acid-etching and rinsing steps by relying on an acidic primer which was responsible for the etching and priming of the smear covered dentin ${ }^{[4]}$. Nowadays, universal or multimode adhesives were developed that merges the bonding components into one bottle and one step procedure. This new technique can be used as total-etching, self-etching or selective demineralization technique ${ }^{[1,2,4]}$.

Based on science of cariology and as stated by Fusyama, dental caries has two distinctive layers, the outer layer consists of caries infected dentin which is highly demineralized and full of bacteria, and should be removed clinically during caries treatment by excavation, and the inner layer which is the caries affected dentin that is partially demineralized and is bacterial free and can be maintained during caries excavation as it can be remineralized ${ }^{[5,6]}$. Studies revealed that bonding to caries affected dentin has lower bond strength than that of normal sound dentin due to its weaker structure that limits resin imoregnation as dentinal tubules is filled with acid resistant mineral deposits beside the formation of thicker hybrid layer ${ }^{[3,7]}$.

The most effective approach to obtain adequate bond strength to dentin was accomplished by the infiltration of the resin monomers inside the demineralized collagen fibril to form the hybrid layer and the creation of resin tags that sealed opened dentinal tubules. The efficacy of these simplified adhesive techniques was still questionable and most of the researches published used sound dentin as bonding substrate while nowadays the old concept of extension for prevention had been replaced by minimal intervention dentistry which advocate minimal removal of hard tooth structure ${ }^{[4]}$, excavation and removal of outer layer that consists of highly infected carious dentin and preserving inner layer of bacteria-free remineralizable caries affected dentin and so clinically most of bonding procedures occurred on caries affected dentin ${ }^{[7,8,9]}$. Previous studies found a decrease in the bond strength of self-adhesive systems to the caries affected dentin, however, that of the newly simplified universal adhesives are less reported and studied ${ }^{[4]}$.

Scanning electron microscopy (SEM) is a reliable method used to analyze dentin structure, and correlate laboratory bond strength results tested with histomorphological structure observed and confirm the results obtained.

Thus, the aim of the current in-vitro study was to evaluate bond strength and study micromorphologi- 
cal features of dentin substrates treated with different etching modes using universal adhesive system.

\section{MATERIALS AND METHODS}

The following materials were used in this study (Table 1):

- Brilliant Everglow (Coltène/Whaledent AG, Altstätten, Switzerland): A2 shade universal composite resin..

- One Coat 7 Universal (Coltène/Whaledent AG, Altstätten, Switzerland): a light-cured, onecomponent bonding agent.

- Seek Caries Indicator (Ultradent Products Inc., Utah, USA): Containing D\&C (Drugs and Cosmetics) dyes in a glycol base.

- Meta Etchant (Meta Biomed Co. Ltd., Chungbuk, Korea): a 37\% Phosphoric acid semi gel used for conditioning of dentin surface.

- Woodpecker Curing Light LED.B ( G u i 1 i n Woodpecker Medical Instrument Co., Ltd., Guangxi, China): LED light curing unit.

\section{Teeth Selection}

A total of 28 freshly extracted human molars with coronal dentin caries were used for this study, of which 12 were used for the bond strength tests and the other 16 were used for micromorphological examinations. Their selection criteria were based on the following:

- Caries were only limited to the occlusal surface, not exceeding two thirds in width of the occlusal surface to ensure that both sound and caries affected dentin were represented in the same tooth.

- The type of the carious lesion was chronic decay, which displayed dark brown or black discoloration when examined visually, but through tactile examination, using an explorer, the carious lesion exhibited was relatively hard in consistency.

\section{Specimens Preparation}

A total of 12 human teeth molars were used for bond strength tests. A permanent marker was used to draw two lines in the selected teeth where the first line represented cemento-enamel junction, while the other line drawn $2 \mathrm{~mm}$ below the first line (C.E.J). Then, double sided diamond disc was used for root sectioning at the level of the second line and crown segments were obtained. A plastic rounded shaped mold of ( $2 \mathrm{~cm}$ diameter, $2 \mathrm{~cm}$ height) was used as mold for embedding the crown segments. The mold was fitted around the crown segment then a chemically cured acrylic resin was mixed and flowed around the crown segment to the level of the cemento-enamel junction.

Double sided diamond disc was then used to grind the occlusal portion of crown segments to obtain flat dentin surface parallel to the occlusal plan under copious amount of coolant. To differentiate between different dentin substrates caries infected, caries affected and sound dentin both clinical evaluation, and caries detection dye material was used. Visually caries affected dentin displayed dark brown or black discoloration; through tactile examination, using an explorer, the carious lesion was relatively hard in consistency. Seek Caries Indicator was used according to the manufacturers' instructions; first applied to the dentin surface for 10 seconds then rinsed for five seconds and then air dried thoroughly. The color of the dentin surface was then observed, the dark blue color representing caries infected dentin, the light blue color denoting caries affected dentin, while the yellow signifying sound dentin. Caries infected dentin which stained dark blue color was removed using sharp spoon excavator.

Each one of the etching modes used in the study was applied on the entire surface of the dentin specimens according to the manufacturers' instructions: 
- Total-etch mode in two steps: Acid etching was performed using 37\% phosphoric acid which was applied on the dentin surface for $15 \mathrm{sec}-$ onds, rinsed with water for 15 seconds and air-dried for 10 seconds leaving dentin moist. Adhesive was applied and gently air thinned for 5 seconds. Then, adhesive was light cured for 20 seconds using Woodpecker Curing Light LED.B (Guilin Woodpecker Medical Instrument Co., Ltd., Guangxi, China).

- Self-etch mode in one step single dose: The adhesive was applied on the dentin surface using disposable applicator and rubbed for $20 \mathrm{sec}-$ onds. Then, a direct gentle steam of air was applied for about 5 seconds until the adhesive film no longer moves. Like other adhesives, light cure was applied for 20 seconds using the same light curing unit.

Brilliant Everglow composite resin was dispersed out of the syringe and was applied using a Teflon coated condenser on the dentin surface, then was covered with a transparent polyster strip and was pressed with a glass slide. The glass slide was then removed leaving the transparent strip in place and the composite was light cured for 20 seconds at zero distance using the same light-curing unit.

For the teeth used for the bond strength test, a transparent polyethylene tube was used to aid in resin composite packing. The transparent polyethylene tube was cut into small irises of $0.2 \mathrm{~mm}$ length using a No.11 sharp lancet. Each resin composite microcylinder obtained was polymerized for 20 seconds using Woodpecker Curing Light LED.B (Guilin Woodpecker Medical Instrument Co., Ltd., Guangxi, China). The polyethylene irises were then cautiously removed after 24 hours by the aid of the lancet, leaving the composite microcylinders bonded to dentin surfaces. A total of four resin composite microcylinders were built over each specimen in which two microcylinders were built on sound dentin and two on caries affected dentin.

\section{Bonding Procedure and Bond Strength Measurement}

A total of 80 composite microcylinders with prepared dentin surface containing both sound dentin and carious affected dentin were used in the study. Specimens were divided into two main groups (40 each) according to the bonding mode used: Selfetch mode in one step single dose, and total-etch mode in two steps. Each group was then subdivided into two subgroups (20 specimens each) according to the type of dentin substrate used: sound dentin and caries affected dentin, as shown hereunder:

- Total-etch mode in two steps bonded to sound dentin

- Total-etch mode in two steps bonded to caries affected dentin

- Self-etch mode in one step single dose bonded to sound dentin

- Self-etch mode in one step single dose bonded to caries affected dentin

All specimens were subjected to micro-shear bond strength ( $\mu \mathrm{SBS})$ testing using a special universal testing machine (Model LRX-plus; Lloyd instruments Ltd., Ferham, UK). The calculation of micro-shear bond strength was done by dividing the load at failure by the bonding area to express the bond strength in MPa according to the following equation:

$$
\begin{aligned}
& \mathrm{S}=\mathrm{P} / \pi \mathrm{r}^{2} \\
& \text { where: } \quad \mathrm{S}=\text { Shear bond strength (in } \mathrm{MPa} \text { ); } \\
& \mathrm{P}=\mathrm{Load} \text { at failure (in Newton); } \\
& \pi=3.14 ; \\
& \mathrm{r}=\text { radius of composite microcylinder (in mm). } \\
& \text { Data was analyzed using Statistical Package for }
\end{aligned}
$$
Social Science software computer program version 23 (SPSS, Inc., Chicago, IL, USA). Data were presented in mean and standard deviation. Student's t-test was used for comparing data. Two way ANOVA was used to detect the effect of etching modes, 
dentin substrates, and the interaction between both of them on micro-shear bond strength (MPa). $P$ value less than 0.05 was considered statistically significant.

\section{Scanning Electron Microscope (SEM) Analysis}

The sixteen teeth that were used for micromorphological examinations were divided into two main groups (8 each) according to the bonding mode used: Self-etch mode in one step single dose, and total-etch mode in two steps. Each group was then subdivided into two subgroups (4 specimens each) according to the type of dentin substrate used: sound dentin and caries affected dentin, as shown here under:

- Total-etch mode in two steps bonded to sound dentin

- Total-etch mode in two steps bonded to caries affected dentin
- Self-etch mode in one step single dose bonded to sound dentin

- $\quad$ Self-etch mode in one step single dose bonded to caries affected dentin

The teeth were sectioned into two halves in a buccolingual direction to expose the interface using low speed diamond disc under copious amount of water. The sections were flattened and smoothed using ascending grits 320, 600 and 1200 of sandpaper discs. The specimens were acid etched using $37 \%$ phosphoric acid gel for $20 \mathrm{~s}$ and rinsed for another 20s to remove smear layer then were immersed in $5 \% \mathrm{NaOCl}$ for $10 \mathrm{~min}$ for deproteinization. The specimens were washed under running water. The interfacial zone was examined using SEM (FEI Company, Netherland) Model Quanta 250 Field Emission Gun (FEG) at magnification $5000 \mathrm{X}$. Interfacial gap distance was measured in micrometers for both enamel and dentin on captured SEM photos.

TABLE (1) Material specifications, manufacturers and compositions

\begin{tabular}{|c|c|c|}
\hline Material & Manufacturer & Descriptions/ Compositions \\
\hline $\begin{array}{l}\text { Brilliant Everglow } \\
\text { (Shade A2) }\end{array}$ & $\begin{array}{l}\text { Coltène/Whaledent AG, } \\
\text { Altstätten, Switzerland }\end{array}$ & $\begin{array}{l}\text { A universal composite of the latest generation } \\
\text { - TEGDMA (5-1\%), BISGMA (5-1\%), zinc oxide coated }(<\% 1.5) \\
\text { - Filler content: } \% 79 w t, \% 69 \text { by volume. } \\
\text { - Inorganic filler content :\%74 wt, \%56 by volume }\end{array}$ \\
\hline One Coat 7 Universal & $\begin{array}{l}\text { Coltène/Whaledent AG, } \\
\text { Altstätten, Switzerland }\end{array}$ & $\begin{array}{l}\text { - Ethanol, ethyl alcohol: } \% 40-35 \\
\text { - Urethane dimethacrylate } \% 25-20 \\
\text { - Hydroxyethyl methacrylate } \% 10-5 \\
\text { - Contains also: 10-MDP (10-Methacryloyloxydecyl dihydrogen } \\
\text { phosphate), Methacrylated polyacid, HEMA, Photoinitiators, } \\
\text { Filler, Water }\end{array}$ \\
\hline Seek Caries Indicator & $\begin{array}{l}\text { Ultradent Products Inc., } \\
\text { South Jordan, Utah, USA }\end{array}$ & $\begin{array}{l}\text { Containing D\&C (Drugs and Cosmetics) dyes in a glycol base, stain } \\
\text { carious dentin. }\end{array}$ \\
\hline Meta Etchant & $\begin{array}{l}\text { Meta Biomed Co. Ltd., } \\
\text { Cheongju-si, Chungbuk, } \\
\text { Korea }\end{array}$ & $\begin{array}{l}37 \% \text { Phosphoric acid semi gel } \\
\text { - Phosphoric acid, } \mathrm{H}_{2} \mathrm{O} \text {, Xanthan gum }\end{array}$ \\
\hline $\begin{array}{l}\text { Woodpecker Curing } \\
\text { Light LED.B }\end{array}$ & $\begin{array}{l}\text { Guilin Woodpecker } \\
\text { Medical Instrument Co., } \\
\text { Ltd., Guangxi, China }\end{array}$ & Light output: $1000 \mathrm{~mW} / \mathrm{cm}^{2}-1200 \mathrm{~mW} / \mathrm{cm}^{2}$ \\
\hline
\end{tabular}


For each tooth, 4 images were taken for each group by Scanning Electron Microscope (SEM).

\section{RESULTS}

This in-vitro study was carried out to assess bond strength and micromorphological features of dentin substrates treated with different etching modes using universal adhesive system.

\section{Results of Micro-Shear Bond Strength $(\mu \mathrm{SBS})$}

Table (2) and Figure (1) showed mean and standard deviation of the micro-shear bond strength ( $\mu \mathrm{SBS}$ ) values (in MPa) of the two etching modes on dentin substrate. For sound dentin using totaletch mode in two steps $(24.02 \pm 1.03 \mathrm{MPa})$ showed statistically significantly lower mean micro-shear bond strength ( $\mu \mathrm{SBS})$ than that using self-etch mode in one step single dose $(28.04 \pm 1.30 \mathrm{MPa})$ at $\mathrm{p}<0.05$. For caries affected dentin using totaletch mode in two steps $(18.46 \pm 0.86 \mathrm{MPa})$ showed statistically significantly higher mean micro-shear bond strength $(\mu \mathrm{SBS})$ than that using self-etch mode in one step single dose $(16.48 \pm 0.84 \mathrm{MPa})$ at $\mathrm{p}<0.05$. Independent of the etch mode used for bonding, sound dentin showed statistically significantly higher mean micro-shear bond strength $(\mu \mathrm{SBS})$ than that of caries affected dentin at $\mathrm{p}<0.05$.

TABLE (2) Mean, Standard Deviation and Significance of Difference of Micro-Shear Bond Strength $(\mu \mathrm{SBS}$ in $\mathrm{MPa})$

\begin{tabular}{|l|c|c|c|c|c|c|}
\hline & \multicolumn{3}{|c|}{ Total-Etch Mode } & \multicolumn{3}{c|}{ Self-Etch Mode } \\
\hline Sound Dentin & 24.02 & \pm & 1.03 & 28.04 & \pm & $1.30^{*}$ \\
\hline $\begin{array}{l}\text { Caries Affected } \\
\text { Dentin }\end{array}$ & 18.46 & \pm & $0.86^{\#}$ & 16.48 & \pm & $0.84^{* \#}$ \\
\hline
\end{tabular}

Data expressed as mean $\pm S D$

SD: standard deviation P: Probability

*: significance vs total-etch mode $(p<0.05)$

\#: significance vs Bonded to sound dentin $(p<0.05)$

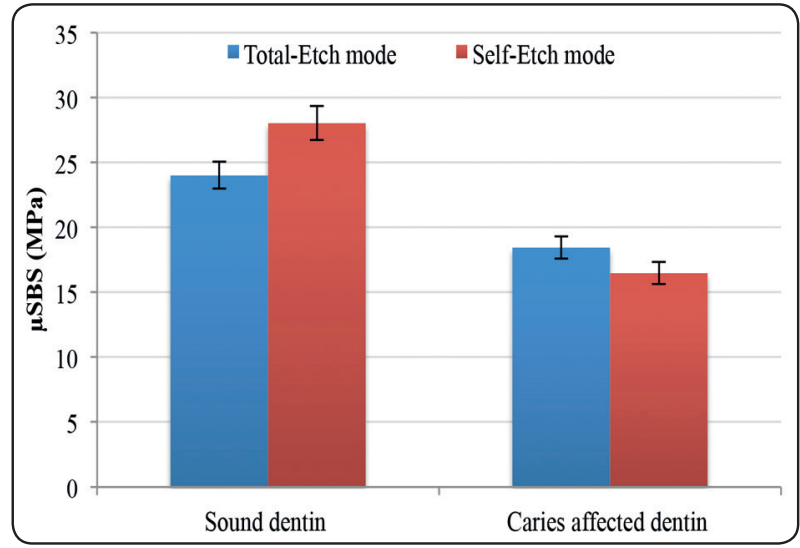

Fig. (1) Bar Chart Representing Mean and SD Values of the Micro-Shear Bond Strength $(\mu \mathrm{SBS})$ of the Two Bonding Modes on Dentin Substrates

Table 3 and Figure 2 represented the results of two way ANOVA that showed statistical significant effect of etching modes (at $\mathrm{P}=0.04$ ), dentin substrates (at $\mathrm{P}<0.001)$, and the interaction between both of them (at $\mathrm{P}<0.001$ and $\mathrm{F}$-value of 42.959 ) on the mean micro-shear bond strength $(\mu \mathrm{SBS})$ at $\mathrm{P}<$ 0.001 . Since the interaction between etching modes and dentin substrates was significant, then they are dependent upon each other.

TABLE (3) representing results of two way ANOVA

\begin{tabular}{|l|c|c|}
\hline & F & P \\
\hline Etching Modes & 4.966 & $0.04 *$ \\
\hline Dentin Substrates & 349.755 & $<0.001^{*}$ \\
\hline $\begin{array}{l}\text { Etching Modes * Dentin } \\
\text { Substrates }\end{array}$ & 42.959 & $<0.001^{*}$ \\
\hline
\end{tabular}

P: Probability *: significance $<0.05$

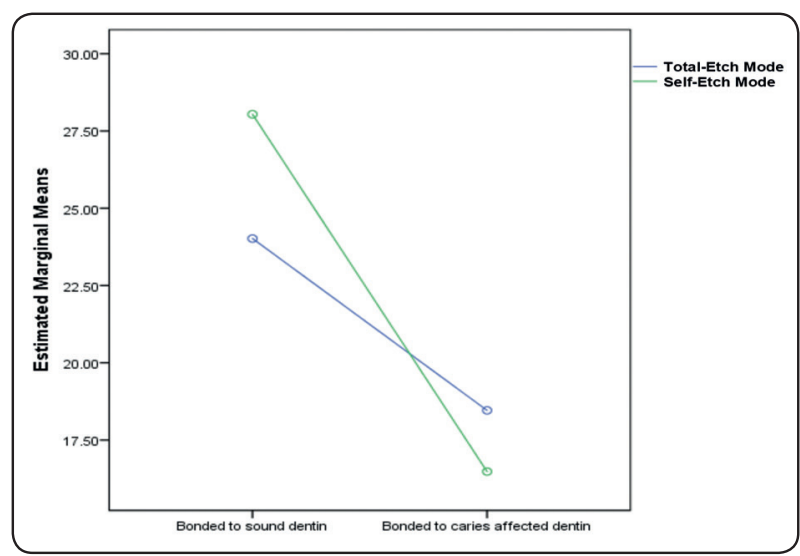

Fig. (2) representing results of two way ANOVA 


\section{Scanning Electron Microscope (SEM) Analysis}

Scanning electron microscopic images of the total-etch mode bonded to sound dentin subgroup revealed that the acid-etched dentin surface was covered by dentin adhesives as shown in figure 4-A. Dentinal adhesives penetrated into the opened dentinal tubules in the form of tags of different length and formed the hybrid layer in the demineralized dentin surface. These resin tags were partially obturating the dentinal tubules. In a deeper part, the resin tags did not reach to the dentinal tubule walls.

Scanning electron microscopic images of the self-etch mode bonded to sound dentin subgroup revealed that the acid-etched dentin surface was covered by dentin adhesives as shown in figure 4-B. Dentinal adhesives penetrated into the opened dentinal tubules in the form of tags of different length and formed the hybrid layer in the demineralized dentin surface. The length of resin tags seemed to be longer than that of adhesives using total-etch mode and they were totally obturating the dentinal tubules.
Scanning electron microscopic images of the total-etch mode bonded to caries affected dentin subgroup revealed that the adhesive resin-infiltrated the demineralized dentin between the overlying adhesive and the underlying demineralized dentin as shown in figure 4-C. The opened dentinal tubules were funnel-shaped due to the dissolution of peritubular dentin in the top of the mineralized dentin zone. The dentinal adhesives were penetrated into the opened dentinal tubules in the form of tags that were broken and shorter. Also, the hybrid layer was shown with thickness 3-4 $\mu$ m which appeared to be well-filled by acid/base-resistant resin.

Scanning electron microscopic images of the self-etch mode bonded to caries affected dentin subgroup revealed that the adhesive resin-infiltrated the demineralized dentin between the overlying adhesive and the underlying demineralized dentin as shown in figure 4-C. Broken and shorter resin tags than the ones present in the Scanning electron microscopic images of the other subgroups were present at the opened dentinal tubules. And thick hybrid layer was shown about 5-6 mm thick and was resistant to acid/base challenge.
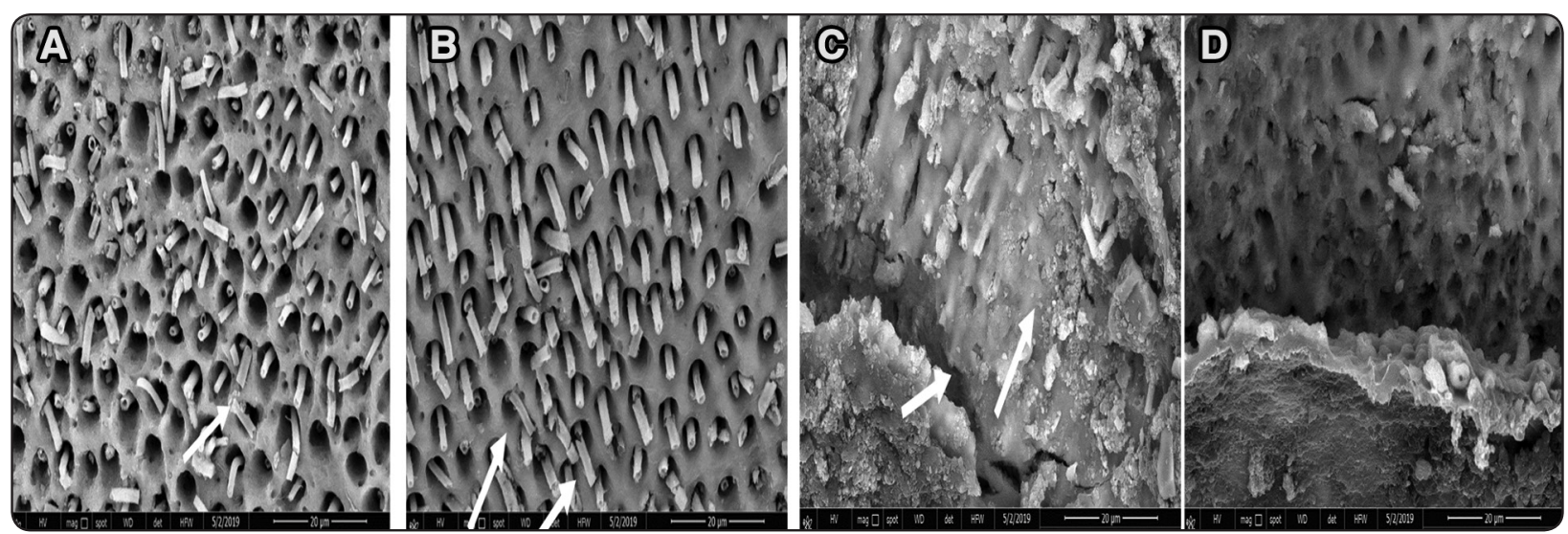

Fig. (3) representing Scanning Electron Microscopic images of all examined subgroups showing: A) Total-etch mode bonded to sound dentin showing the penetration of adhesives into the dentinal tubules in form of resin tags (arrows). B) Self-etch mode bonded to sound dentin showing the penetration of adhesives into the opened dentinal tubules in form of resin tags which are long (arrows). C) Total-etch mode bonded to caries affected dentin showing the penetration of adhesives into the dentinal tubules in form of funnel-shaped resin tags (arrows). Presence of thick hydride layer 3-4mm. D) Self-etch mode bonded to caries affected dentin showing the penetration of adhesives into the dentinal tubules in form of broken-shaped resin tags. Presence of thick hydride layer $5-6 \mathrm{~mm}$. 
Independent from the etching mode used and when comparing the scanning electron microscopic images of the bonded dentin substrates (figure 4-A and $\mathrm{B})$, the sound dentin revealed more penetration of dentinal adhesives into the opened dentinal tubules in the form of resin tags which were longer and totally obturating the dentinal tubules to achieve the optimal bonding to dentin than that of caries affected dentin (figure 4-C and D). In addition, the SEM images also revealed increase in the thickness of hybrid layer in caries affected dentin than sound dentin signifying decrease in bond strength.

\section{DISCUSSION}

Technology and innovations in the science of adhesive dentistry have led to improvements in the quality of bonding which resulted in more effective adhesions with less technique sensitive during application ${ }^{[2]}$. A lot of studies have been conducted on many types of adhesives. Recently, a more versatile bonding system was developed that can be used as total-etch mode in two steps, self-etch mode in one step, selective demineralization technique, and so called multipurpose, multimode or universal adhesives. They are characterized by their simplicity and being less technique sensitive as they are supplied as one bottle systems ${ }^{[1,2,10]}$.

Regarding teeth selection, in this study, human carious molars were selected with carious lesion on the occlusal surface rather than proximal surface that had more liability for being exposed, and so caries affected dentin was accurately obtained from molars occlusal surface surrounded by sound dentin ${ }^{[7,11]}$. Also the types of decay present in molars were chronic caries rather than acute caries, since the incidence of pulp exposure is more likely to occur in acute caries.

Different available methods were commonly used to distinguish between caries infected dentin and caries affected dentin; from which was the tactile method that could be judged by assessment of the remaining dentin hardness; another method was the color of the remaining dentin, which was considered as a subjective method for caries infected dentin removal. Those two methods were not fully reliable, so a more confirmatory method using caries detection dye was used in this study, in which dye stains the outer surface that contained caries infected dentin and facilitate its removal by excavation. Many reports have proven that specifically Seek Caries Indicator had no effect on adhesive bond strength, this was why it was selected to be used in the current study ${ }^{[6,12,13]}$.

Micro-shear and micro-tensile tests are the two measurement tools that were widely used to evaluate the bond strength of dental adhesives. In this research, micro-shear bond strength ( $\mu \mathrm{SBS})$ was selected as it provided bond strength evaluation at standardized regions which in turn preserved the uniformity of the tested areas, in addition, it was considered a relatively simple test for specimens' preparations [7,14M15].

Scanning electron microscope (SEM) analysis was also used in the study herein. As it helped to correlate laboratory investigation results obtained with the micromorphological structure of the dentin substrate revealed from scanned photos, and hence more confirmatory results was achieved.

In the present study, sound dentin showed statistically significantly higher mean micro-shear bond strength $(\mu \mathrm{SBS})$ than that of caries affected dentin at $p<0.05$. This finding was in agreement with Costa et al. and also with Yoshiyama et al. This may be attributed to the fact that caries affected dentin consists mostly of weaker demineralized structure which is porous with high water content and decreased mechanical properties, and the dentinal tubules found were filled with acid resistant mineral deposits which limited and decreased adhesive resin infiltration, and formed an unusual structure of the hybrid layer in the demineralized dentin surface, that is thicker as a result of deep monomer 
penetration ${ }^{[6,13,16]}$. In contrast, Shadman et al. found that there were no statistical significant difference in bond strength between sound and caries affected dentin ${ }^{[6]}$. Also, the results of this study contradicted with that of Nakornchai et al. and Tosun et al. , who found that caries affected dentin had higher bond strength than that of sound dentin, this may be because of the difference in adhesive methodology or technique ${ }^{[17,18]}$. The finding of the current study was confirmed by SEM examination that revealed increase in the number and length of resin tags which totally obturated dentinal tubules with high penetration into demineralized dentin regions, signifying better bonding to sound dentin than to caries affected dentin.

In this study, using total-etch mode -or so called etch and rinse mode- had statistically significantly better bonding strength to caries affected dentin $(18.46 \pm 0.86 \mathrm{MPa})$ than using self-etch mode $(16.48 \pm 0.84 \mathrm{MPa})$. This finding was in agreement with Costa et al. and Ceballos et al. who have discussed that dentinal tubules of the caries affected dentin are filled with acid resistant mineral deposits that interfere with adhesive resin infiltration and so the microstructural formation of resin tags was greatly affected. And this was confirmed in the SEM images that revealed increase in the thickness of hybrid layer for self-etch mode bonded to caries affected dentin more than that of total-etch mode denoting a decrease in bond strength of self-etch mode. When using $37 \%$ phosphoric acid in the totaletch mode, this might contribute in dissolving this mineral deposits inside dentinal tubules of caries affected dentin leading to the opening of the tubules and resulted in more resin infiltration and retention than that of self-etch mode due to its weaker acids constituents. Moreover, in the self-etch mode, the smear layer contained acid resistant minerals that limited the diffusion of the adhesive resin into caries affected dentin and led to decreasing its bonding strength ${ }^{[4,13,19]}$.
On the other hand, this research disclosed that the use of self-etch mode on sound dentin $(28.04 \pm 1.30$ $\mathrm{MPa})$ had statistically significantly higher bond strength than that of total-etch mode $(24.02 \pm 1.03$ $\mathrm{MPa})$. These results were in agreement with that of Müller et al. who found superior bonding results using single-bond universal on sound dentin to Prime and Bond NT ${ }^{[7]}$. This may be attributed to the fact that one coat 7 univeral adhesive, used in this study, is versatile and can be used as both etch and rinse mode or as self-etch mode; and that the only difference between the two modes was the use of $37 \%$ phosphoric acid in case of the self-etch mode; while the application of the phosphoric acid as a separate step did not improve bond strength results on sound dentin. The unique composition of one coat 7 universal containing 10-MDP which is considered as a phosphorate monomer which contribute in the adhesive acidic character, which in turn allowed for resin infiltration and adequate demineralization. Also 10-MDP had the ability to form chemical bond with tooth minerals improving the durability of adhesion formed ${ }^{[20,21]}$. In contrast, Isolan et al. found that there was no statistical significant difference between total-etch mode and self-etch mode of Scotch bond universal on sound dentin ${ }^{[1]}$. The finding of the current study was confirmed by SEM examination that revealed increase in the length of resin tags of self-etch mode on sound dentin to be longer than that of total-etch mode on sound dentin, indicating more resin infiltration occurred in the sound dentin bonded using self-etch mode.

In this research, the analysis of the scanning electron microscope (SEM) confirmed the microshear bond strength results and revealed low resin tag formation in case of caries affected dentin and showed ticker hybrid layer than that of sound dentin. Moreover, more resin tags were formed in total-etch mode of universal adhesive than in the self-etch mode indicating more resin infiltration inside dentinal tubules. 
The decrease of micro-shear bond strength of the caries affected dentin may not represent a chemical problem if there is normal or sound dentin surrounding it that could increase resin infiltration and increase bond strength ${ }^{[22]}$.

\section{CONCLUSIONS}

Under the limitations of this in-vitro study, the following conclusions could be deducted:

- The type of substrate and etching strategies may affect the bonding performance and durability of restorations in dentistry.

- Using self-etch of universal adhesives on sound dentin is considered to be material dependent.

- Self-etching on dentin in one step without using pretreatment with acid gives favorable results regarding adhesive bond strength on sound dentin.

- Using total-etch mode of universal adhesive on caries affected dentin can enhance bond strength.

- Measuring bond strength of dentin substrates while aging is crucial in correlation of the invitro studies with clinical trials as this may give more confirmatory results about the clinical effectiveness of universal adhesives.

\section{REFERENCES}

1. Isolan CP, Valente LL, Münchow EA, Basso GR, Pimentel AH, Schwantz JK, da Silva AV, Moraes RR. Bond strength of a universal bonding agent and other contemporary dental adhesives applied on enamel, dentin, composite, and porcelain. Applied Adhesion Science. 2014; 2:25.

2. Diniz AC, Bandeca MC, Pinheiro LM, Dos Santosh Almeida LJ Jr, Torres CR, Borges AH, Pinto SC, Tonetto MR, De Jesus Tavarez RR, Firoozmand LM. Influence of Different Etching Modes on Bond Strength to Enamel using Universal Adhesive Systems. J Contemp Dent Pract. 2016 Oct $1 ; 17(10): 820-825$.

3. Koyuturk AE, Sengun A, Ozer F, Sener Y, Gokalp A. Shear bond strengths of self-etching adhesives to caries-affected dentin on the gingival wall. Dent Mater J. 2006 Mar; 25(1):59-65.
4. Ceballos L, Camejo DG, Victoria Fuentes M, Osorio R, Toledano M, Carvalho RM, Pashley DH. Microtensile bond strength of total-etch and self-etching adhesives to caries-affected dentine. J Dent. 2003 Sep; 31(7):469-477.

5. Shibata S, Vieira LC, Baratieri LN, Fu J, Hoshika S, Matsuda Y, Sano H. Evaluation of microtensile bond strength of self-etching adhesives on normal and cariesaffected dentin. Dent Mater J. 2016; 35(2):166-173.

6. Shadman N, Farzin-Ebrahimi S, Mortazavi-Lahijani E, Ghaderi A. Shear bond strength of different adhesive systems to normal and caries-affected dentin. J Oral Health Oral Epidemiol. 2015 Apr; 4(2):87-93.

7. Müller C, Rosa GC, Teixeira GS, Krejci I, Bortolotto T, Susin AH. Effect of caries-affected dentin on one-step universal and multi-step etch-and-rinse adhesives' bond strength. Rev Odontol UNESP. 2017 Oct; 46(5):273-277.

8. Sacramento PA, de Castilho AR, Banzi EC, Puppi-Rontani RM. Influence of cavity disinfectant and adhesive systems on the bonding procedure in demineralized dentin - a one-year in vitro evaluation. J Adhes Dent. 2012 Dec; 14(6):575-583.

9. Yoshiyama M, Tay FR, Doi J, Nishitani Y, Yamada T, Itou K, Carvalho RM, Nakajima M, Pashley DH. Bonding of self-etch and total-etch adhesives to carious dentin. J Dent Res. 2002 Aug; 81(8):556-560.

10. Milia E, Pinna R, Castelli G, Bortone A, Marceddu S, Garcia-Godoy F, Gallina G. TEM morphological characterization of a one-step self-etching system applied clinically to human caries-affected dentin and deep sound dentin. 2012 Dec; Am J Dent, 25(6):321-326.

11. Kassa D, Day P, High A, Duggal M. Histological comparison of pulpal inflammation in primary teeth with occlusal or proximal caries. Int J Paediatr Dent. 2009 Jan; 19(1):26-33.

12. Alleman DS, Magne P. A systematic approach to deep caries removal end points: the peripheral seal concept in adhesive dentistry. Quintessence Int. 2012 Mar; 43(3):197208.

13. Costa AR, Garcia-Godoy F, Correr-Sobrinho L, Naves LZ, Raposo LHA, Carvalho FG, Sinhoreti MAC, PuppinRontani RM. Influence of Different Dentin Substrate (Caries-Affected, Caries-Infected, Sound) on Long-Term $\mu$ TBS. Braz Dent J. 2017 Feb; 28(1), 16-23.

14. El Zohairy AA, Saber MH, Abdalla AI, Feilzer AJ. Efficacy of microtensile versus microshear bond testing 
for evaluation of bond strength of dental adhesive systems to enamel. Dent Mater. 2010 Sep; 26(9):848-854.

15. Tedesco TK1, Montagner AF, Skupien JA, Soares FZ, Susin AH, Rocha RO. Starch tubing: an alternative method to build up microshear bond test specimens. J Adhes Dent. 2013 Aug; 15(4):311-315.

16. Wang Y, Spencer P, Walker MP. Chemical profile of adhesive/caries-affected dentin interfaces using Raman microspectroscopy. J Biomed Mater Res A. 2007; 81(2):279-286.

17. Nakornchai S1, Harnirattisai C, Surarit R, Thiradilok S. Microtensile bond strength of a total-etching versus selfetching adhesive to caries-affected and intact dentin in primary teeth. J Am Dent Assoc. 2005 Apr; 136(4):477-483.

18. Tosun G, Koyuturk AE, Sener Y, Sengun A. Bond strength of two total-etching bonding systems on caries-affected and sound primary teeth dentin. Int J Paediatr Dent. 2008 Jan; 18(1):62-69.

19. Nakajima M, Sano H, Zheng L, Tagami J, Pashley DH. Effect of moist vs. dry bonding to normal vs. cariesaffected dentin with Scotchbond Multi-Purpose Plus. J Dent Res. 1999 Jul; 78(7):1298-1303.

20. Van Meerbeek B1, Yoshihara K, Yoshida Y, Mine A, De Munck J, Van Landuyt KL. State of the art of self-etch adhesives. Dent Mater. 2011 Jan; 27(1):17-28.

21. Muñoz MA, Luque I, Hass V, Reis A, Loguercio AD, Bombarda NH. Immediate bonding properties of universal adhesives to dentine. J Dent. 2013 May; 41(5):404-11.

22. Mertz-Fairhurst EJ, Curtis JW Jr, Ergle JW, Rueggeberg FA, Adair SM. Ultraconservative and cariostatic sealed restorations: results at year 10. J Am Dent Assoc. 1998 Jan; 129(1):55-66. 